\title{
Laccase/2,2,6,6-tetramethylpiperidinoxyl radical (TEMPO): an efficient catalytic system for selective oxidations of primary hydroxy and amino groups in aqueous and biphasic media
}

\author{
Alba Díaz-Rodríguez, ${ }^{\mathrm{a}}$ Lía Martínez-Montero, ${ }^{\mathrm{a}}$ Iván Lavandera, ${ }^{\mathrm{a}}$ Vicente Gotor ${ }^{\mathrm{a}}$ and \\ Vicente Gotor-Fernández ${ }^{\mathrm{a}, *}$ \\ a Department of Organic and Inorganic Chemistry, Instituto Universitario de Biotecnología de Asturias, University of \\ Oviedo, Avenida Julián Clavería s/n, 33006 Oviedo, Spain. E-mail: vicgotfer@ uniovi.es
}

Received: ((will be filled in by the editorial staff))

Supporting information for this article is available on the WWW under http://dx.doi.org/10.1002/adsc.201\#\#\#\#\#\#.

Abstract. Copper salts /2,2,6,6-tetramethylpiperidinoxyl radical (TEMPO) catalytic systems enable efficient aerobic oxidations of primary alcohols but they generally show a reduced reactivity in aqueous medium. Herein, we report an oxidative catalytic system composed of Trametes versicolor laccase and TEMPO, which is able to work in buffer solutions at room temperature using ambient air. Although this catalytic system displays great efficiency in aqueous systems, the addition of methyl tert-butyl ether allows the reduction of TEMPO loading, also enhancing the solubility of hydrophobic compounds. This practical methodology promotes the chemoselective aerobic oxidation of hydroxy or amino groups, leading to interesting organic derivatives such as aldehydes, lactones, hemiaminals or lactams.

Keywords: aerobic oxidation; hemiaminals; laccase/TEMPO; lactones; selective oxidation.

\section{Introduction}

The controlled oxidation of alcohols to obtain aldehydes, ketones or carboxylic acid derivatives is one of the most challenging transformations in organic chemistry. A great number of stoichiometric reagents have been employed for performing oxidation reactions such as peroxides, hypervalent organoiodane, chromium oxides or sulfur-based reagents. ${ }^{[1]}$ However, current environmental concerns are pressuring industries to replace toxic reagents and develop novel approaches able to operate in more benign conditions.

In this context, catalytic oxidations using transition metal agents under aerobic conditions are becoming more relevant as oxygen produces water as the only by-product. ${ }^{[2]}$ Among them, Cu-containing complexes have emerged as the most potent ones in the past few years. On the other hand, biocatalytic oxidations are presently considered as well-established approaches, to obtain valuable compounds under mild reaction conditions, which are difficult to prepare by conventional chemical strategies. ${ }^{[3]}$ Actually, $\mathrm{Cu}^{2+}$ dependent oxidases have received great attention in recent years.

In particular, laccases that belong to the so-called blue-copper oxidases have been identified as promising candidates to achieve eco-friendly oxidations. These enzymes, which are found in many fungi, plants and bacteria, catalyze the oxidation of electron rich aromatic substrates, typically phenols or aromatic amines ${ }^{[4]}$ via four single electron oxidation steps resulting in the reduction of $\mathrm{O}_{2}$ to $\mathrm{H}_{2} \mathrm{O}$, and formation of the corresponding radicals that can undergo different pathways to form more complex molecules. Unfortunately, laccases are not effective towards non-phenolic substrates and an electron transfer mediator (Med, Scheme 1a) is required. Mediators act as 'electron shuttles' which, after being oxidized by the laccase (Laccase ${ }_{\text {ox }}$ ), diffuse away from the active site to oxidize a non-natural substrate (Substrate ${ }_{\text {red }}$ ). Traditionally, 2,2'-azino-bis(3ethylbenzothiazoline-6-sulphonic acid, ABTS), 1hydroxybenzotriazole (HBT), $N$-hydroxyphthalimide (HPI), or 2,2,6,6-tetramethylpiperidinoxyl radical (TEMPO) have been used as electron transfer mediators together with laccases for selective oxidation reactions, ${ }^{[5]}$ TEMPO and its derivatives being extensively studied for redox processes. ${ }^{[5 \mathrm{~d}, \mathrm{sh}, 6]}$ Hence, this laccase/TEMPO chemoenzymatic system has been efficiently employed to achieve the oxidation of primary ${ }^{\{5 h, 7]}$ and secondary alcohols. ${ }^{[5 h, 7 a, 8]}$ In recent years, this field is quickly progressing, and a novel series of mediators has been described for aerobic oxidations. ${ }^{[9]}$ Additionally, TEMPO in combination with other chemical oxidants have delivered mild routes towards fine chemicals with excellent selectivities. For instance, metal catalysts can be used to generate the oxoammonium ion, ${ }^{[10]}$ but also hypochlorite, that oxidizes alcohols under slightly basic conditions at $0-4{ }^{\circ} \mathrm{C}$ (known as Anelli-Montanari process). ${ }^{[11]}$ 
a)

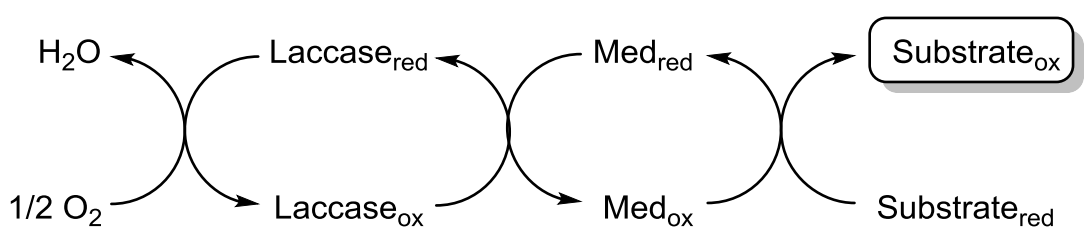

b)

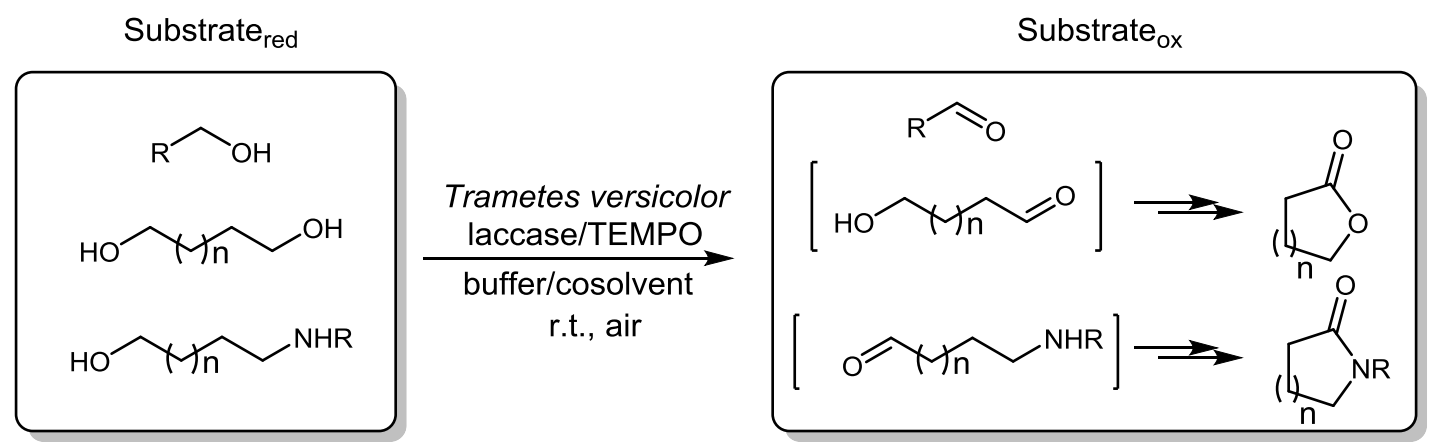

Scheme 1. a) The role of the mediator in oxidation reactions conducted by laccases; and b) an overview of the reactions scrutinized in this study using the Trametes versicolor laccase/TEMPO system.

Based on this background and as part of our continued interest in adapting biocatalytic methods to organic synthesis, we have considered worthwhile to explore the selective oxidation of different alcohols, diols and amino alcohols using Trametes versicolor laccase (a $\mathrm{Cu}$-dependent oxidase) together with TEMPO to efficiently obtain interesting aldehydes, lactones or lactams (Substrate ${ }_{\mathrm{ox}}$, Scheme 1b). In this context, it is vital to develop greener synthetic strategies for their synthesis, since most of the methodologies that have been developed hitherto are conducted in organic solvents and/or at high temperatures. These derivatives are of interest for industry. For example, aldehydes are of commercial interest as fragrances and flavors, while lactones and lactams are relevant classes of compounds with wide number of applications due to their pharmaceutical and biological activities. ${ }^{[12]}$

\section{Results and Discussion}

The catalytic potential of laccases in organic synthesis has been intensely studied, ${ }^{[13]}$ however, their main applications have been restricted for a long time to delignification processes. In a search for greener protocols, we have recently developed a $T$. versicolor laccase/TEMPO catalytic system able to oxidize aliphatic $1, \omega$-diols in aqueous medium for the preparation of achiral and racemic lactones. ${ }^{[14]}$ Oxidation reactions were conducted at room temperature in $\mathrm{NaOAc}$ buffer $(50 \mathrm{mM}, \mathrm{pH} 4.8)$, open to ambient air and with the commercial laccase from Trametes versicolor and $20 \% \mathrm{~mol}$ of TEMPO (Scheme 2). Under these conditions, we observed that the monooxidation of a hydroxyl group was favored, obtaining the hydroxy aldehyde. Then, the corresponding aldehyde underwent spontaneous cyclization leading to the unstable hemiacetal, which was reoxidized obtaining the corresponding lactone. This practical methodology allowed the formation of the targeted lactones in a selective manner with quantitative yields (>97\%) and high purity after a simple extraction protocol.

At this point, we decided to check the compatibility and applicability of our system under other reaction conditions. Firstly, we observed that parameters such as aeration and stirring were crucial for a successful transformation towards the desired lactones. Therefore, we have performed these oxidation reactions in an open tube with vigorous stirring (Scheme 2). By using these conditions, bubbling of oxygen or air was not necessary to achieve total conversions. We also evaluated the effect of the temperature on the lactonization process. Therefore, the aerobic oxidation of 3-phenyl-1,5pentanediol $(1,30 \mathrm{mM})$ was performed at $20{ }^{\circ} \mathrm{C}, 30$ ${ }^{\circ} \mathrm{C}$ and $45^{\circ} \mathrm{C}$ obtaining the corresponding lactones with excellent conversions after 12 h (>97\%, Figure S1). Moreover, the undesired hydrolysis of the lactone to the carboxylic acid was not detected in any case under these reaction conditions. 


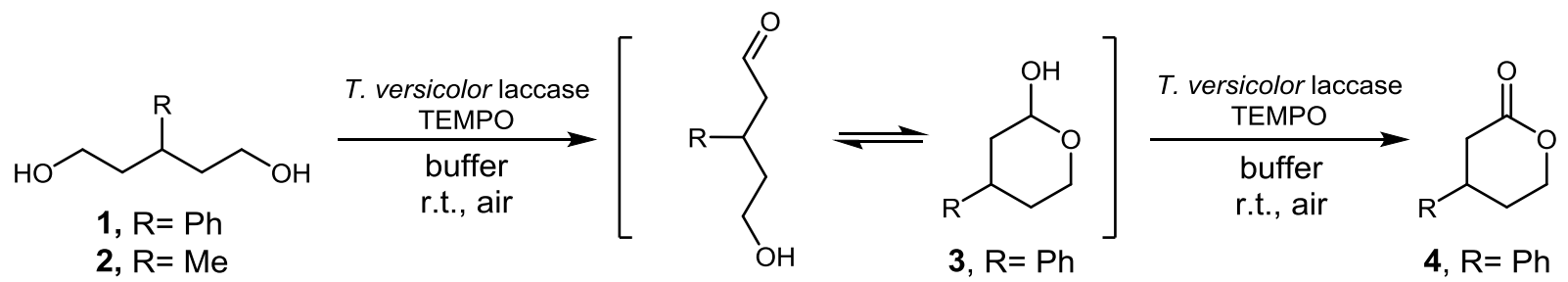

Scheme 2. Aerobic oxidation of diols $\mathbf{1}$ and $\mathbf{2}$ using the Trametes versicolor laccase/TEMPO system.

We next examined the influence of the $\mathrm{pH}$ on the aerobic oxidation of diol $\mathbf{1}$. On the basis of the experimental results, we can indicate that the Trametes versicolor laccase/TEMPO system catalyzed the lactonization reaction in an efficient manner in aqueous media when $\mathrm{pH}$ ranged from 4.8 to 6.5 , although the rate of the cyclization was optimum around $\mathrm{pH} 5.5$ (Figure $\mathrm{S} 2$ ). At higher $\mathrm{pH}$ values $(\mathrm{pH}=7)$, a drastic decrease in the activity was observed due to the laccase inactivation. It is important to remark that this catalytic system was compatible with acetate, citrate and phosphate buffer ranging from $\mathrm{pH}$ 4.8-6.5.

Other oxidases. Based on the excellent results achieved with this Trametes versicolor laccase/TEMPO system, we decided to investigate whether different oxidases could take part in the same lactonization reaction. For that purpose, a set of available enzymes were screened in the lactonization of diols 1 and $\mathbf{2}$ (Figure 1). Trametes sp., Cerrena unicolor, Myceliophthora thermophila, and Pleurotus ostreatus were employed. Trametes versicolor laccase was the most active followed by Trametes sp. laccase, while other enzymes such as Bacillus subtilis laccase as well as an alcohol oxidase from Pichia pastoris did not show any activity in the oxidation of diols 1 and 2. Furthermore, other mediators were tested for this reaction without any improvement as previously reported (see Figure S3). ${ }^{[5 f]}$

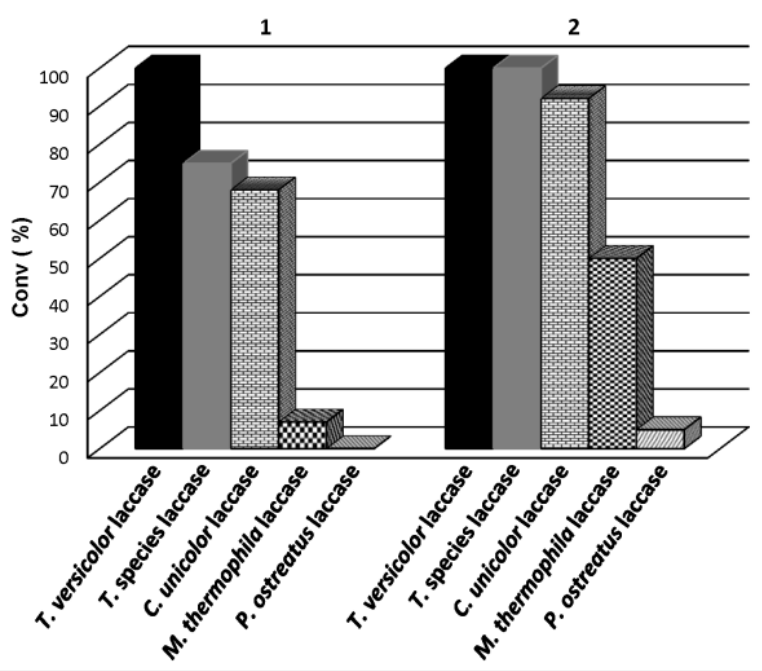

Figure 1. Oxidation of diols 1 and 2 (30 mM) using different oxidases $(t=12 \mathrm{~h})$.
Cosolvent addition. During the course of this investigation it was clear that the laccase from Trametes versicolor/TEMPO dyad was the most efficient for the oxidation of interesting aliphatic diols in a regio- and/or monoselective fashion. However, although great yields were observed, 15$20 \%$ mol of mediator was necessary to complete the reaction (Figure 2).

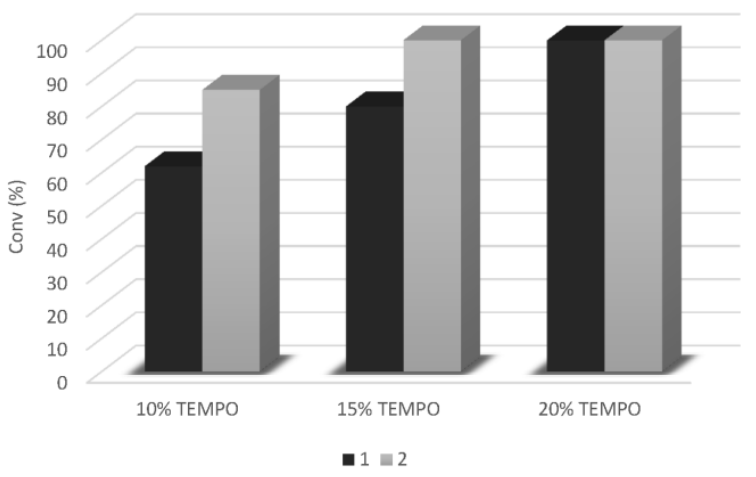

Figure 2. Effect of the concentration of TEMPO (\% mol) on the aerobic oxidation of $\mathbf{1}$ and $\mathbf{2}(30 \mathrm{mM})$ with $T$. versicolor laccase $(t=12 \mathrm{~h})$.

To overcome this limitation and make this chemoenzymatic approach more competitive, we decided to optimize additional reaction parameters. Therefore, we studied the cosolvent effect for the aerobic oxidation of $\mathbf{1}$ as a model substrate. In one hand the solubility of the substrate can be alleviated, and on the other hand the stability of the mediator in the organic solvent can be increased. ${ }^{[15]}$ In a first attempt, acetonitrile was added to the reaction. Oxidation of aliphatic diols was recently reported to take place efficiently in acetonitrile using $\mathrm{Cu}$ complexes [(bpy) $\mathrm{Cu}^{\mathrm{I}}$ ] together with TEMPO and $\mathrm{N}$ methylimidazole (NMI) as catalytic system. ${ }^{[16]}$ Additionally, laccases have shown great activity in such media. ${ }^{[17]}$ Although the laccase/TEMPO system remained active when using a significant amount of acetonitrile (20-30\% v/v, Figure 3), little improvements were achieved in terms of the reaction rate and TEMPO concentration. This decrease in the activity can be caused by enzyme denaturalization or inhibition issues. ${ }^{[18]}$ 


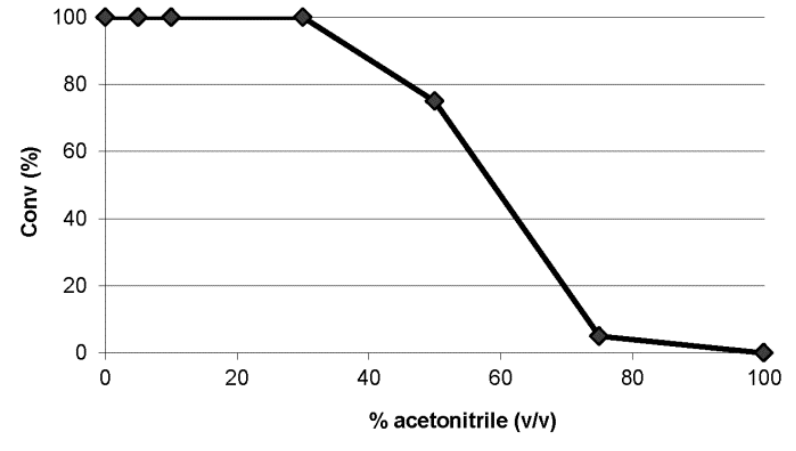

Figure 3. Effect of the percentage of acetonitrile on the aerobic oxidation of $\mathbf{1}$.

In light of these results, we evaluated the use of other cosolvents which were previously employed in similar oxidation studies such as acetone, dioxane, DMSO, EtOAc, toluene or methyl tert-butyl ether (MTBE, Tables S1 and S2). ${ }^{[18,19]}$ Interestingly, the best results in terms of conversion and reaction rates were obtained with MTBE. At this point, it is important to highlight that this catalytic system was compatible with the addition of cosolvents and that this aerobic oxidation could be conducted in monoand biphasic systems. Moreover, we should remark that an important percentage of MTBE was accepted (up to $85 \% \mathrm{v} / \mathrm{v}$, Table S2) without decrease of the activity (conversion $>97 \%$ in $9 \mathrm{~h}$ ), allowing the oxidation of this hydrophobic diol.

Based on these findings in the presence of this non-miscible organic solvent, we next studied if under these biphasic conditions the mediator concentration could be reduced leading to similar conversion values. Gratifyingly, when MTBE (50\% $\mathrm{v} / \mathrm{v}$ ) was used, $5-10 \%$ mol of TEMPO was able to oxidize diols $\mathbf{1}$ and $\mathbf{2}$ efficiently towards the corresponding lactones after $16 \mathrm{~h}$ (yields $>90 \%$ ). We should point out that when $5 \%$ mol of mediator was employed, longer reaction times ( $24 \mathrm{~h})$ were required. To demonstrate whether these conditions could further improve our previous method, we decided to operate semi-continuously. This issue is critical for the development of a more efficient, economic and profitable process. In this particular case, $\mathbf{1}$ was continuously dosed into the reactor system and in situ extracted to the organic phase. In this way, 0.12 mmol of $\mathbf{1}$ in citrate buffer/MTBE $(50 \% \mathrm{v} / \mathrm{v})$ were treated with $10 \%$ mol of TEMPO and $8 \mathrm{U} / \mathrm{mL}$ of laccase for $16 \mathrm{~h}$. Subsequently, the retreatment of this system with additional $0.12 \mathrm{mmol}$ and $5 \% \mathrm{~mol}$ of TEMPO led to the final lactone $\mathbf{4}$ from diol $\mathbf{1}$ in $\mathbf{9 0 \%}$ conversion after additional $16 \mathrm{~h}$.
Other chemical methods. To test the viability and competitiveness of our protocol, we screened some of the most notable TEMPO-mediated alcohol oxidation methods employed nowadays using diol $\mathbf{1}$ as model compound. In this way, $\mathrm{NaOCl}$ or $\mathrm{NaOCl} / \mathrm{NaOCl}_{2}$ were firstly employed as co-oxidants. These reactions were therefore performed in mixtures of organic solvent/water or in buffer using $20 \% \mathrm{~mol}$ of TEMPO. However in these cases, other by-products were detected in the reaction crudes, also finding that an excess of $\mathrm{NaOCl}$ was necessary to achieve high conversions after $12 \mathrm{~h}(\mathrm{conv}=71 \%)$.

Moreover, other metal salts and complexes were tested as co-catalysts in the lactonization reaction of diol 1 (Table 1). Regarding the copper-catalyzed methods, several mild oxidation procedures have been described, although most of them make use of organic solvents (Table 1, entries 1-9). ${ }^{[20]}$ As a general observation, $\mathrm{Cu}$ (II) salts led to better results than the corresponding $\mathrm{Cu}(\mathrm{I})$ salts (Table 1, entries 18 ), since the last ones gave access to the hemiacetal $\mathbf{3}$ as the major product (Table 1 , entries 3 and 4). Moreover, the presence of both ligands and bases was crucial for the success of the oxidation. This is due to the fact that bipyridine (Bpy) or phenantroline (Phen) ligands are required to increase the solubility of copper in the reaction mixture and enhance the electronic properties of the metal. ${ }^{[21]}$ For example, when $\mathrm{CuBr}_{2}$ was used in combination with Phen or Bpy and ${ }^{\mathrm{t}} \mathrm{BuOK}$ as base (Table 1, entries 7 and 8), lactone 4 could be detected in a $42-50 \%$ conversion, however, significant amounts of hemiacetal $\mathbf{3}$ were also observed. We must mention that when CuOTf was used as copper source together with Bpy in acetonitrile and NMI as base, ${ }^{[16]}$ lactone $\mathbf{4}$ was obtained with an excellent yield (Table 1, entry 9).

We also tested other metal-based catalytic systems reported in the literature for the preparation of similar compounds (Table 1, entries 10-13). ${ }^{[22]}$ Under these conditions, lactone $\mathbf{4}$ was detected but with incomplete conversions or as a mixture of products, except for the case of Shvo's catalytic system where conversion was $93 \%$ (Table 1, entry 12).

These results highlight the exceptional efficiency and potential of using laccase and TEMPO without employing any exogenous base or additional ligands in aqueous or biphasic media, to decrease the TEMPO loading or improve the solubility of the reactants (Table 1, entries 14 and 15). Additionally, oxidations with our catalytic system were conducted at room temperature whereas some of the tested methods required more drastic reaction conditions. 
Table 1. Oxidation of diol 1 using different catalytic systems. ${ }^{[a]}$

\begin{tabular}{lllllllll} 
& & & & & & & & \\
\hline
\end{tabular}

[a] See ESI for further details. [b] Conversions and ratios were determined by NMR.

Oxidation of other diols and alcohols. Once established suitable conditions for our system, we decided to explore the scope of this chemoenzymatic approach towards the oxidation of 1, $\omega$-diols 5-10 (Figure 4). Experiments were carried out using MTBE as cosolvent $(50 \% \mathrm{v} / \mathrm{v})$ at room temperature, open to air and reducing the amount of TEMPO to $10 \%$ mol. In all cases, conversions were higher than $85 \%$ after $12 \mathrm{~h}$, showing the excellent performance of this catalytic system as well as its selectivity and compatibility with these types of substrates.

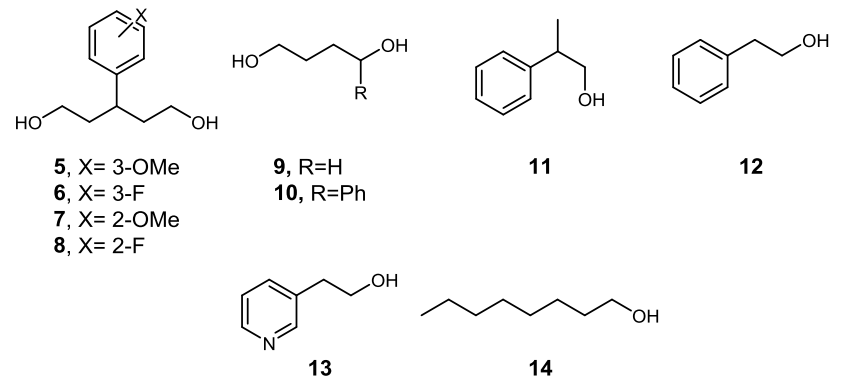

Figure 4. Other tested alcohols using $T$. versicolor laccase/TEMPO.

Then, we decided to explore the potential of our catalytic system over other primary alcohols of interest (11-14, Figure 4). Among them, a profen-like derivative (11) was envisioned as a good target compound. These derivatives are highly valuable for industry and have also attracted the attention of academia. ${ }^{[23]}$ In all cases, from good to very good yields were obtained towards the formation of the corresponding aldehydes in 2.5-7 h (Table 2). Some limitations were identified for these oxidation reactions: i) long reaction times led to overoxidation, and therefore the use of $20 \%$ mol TEMPO was optimized to accelerate the reaction and minimize the formation of the carboxylic acid; ii) the use of MTBE did not improve either reaction rates or conversions; and iii) evaporation of the products can occur over the course of the reaction since all the reactions were carried out in open tubes. To minimize this loss, a perforated aluminum foil was used in order to increase the isolated yield.

Table 2. Oxidation of substrates 11-14 using laccase and TEMPO. ${ }^{[\mathrm{a}]}$

\begin{tabular}{llll}
\hline Entry & Substrate & $\mathrm{t}[\mathrm{h}]$ & conv $[\%]^{[\mathrm{b}]}$ \\
\hline 1 & $\mathbf{1 1}$ & 2.5 & $95(15)$ \\
2 & $\mathbf{1 2}$ & 3 & $90(7)$ \\
3 & $\mathbf{1 3}$ & 5 & $85(<3)$ \\
$4^{[\mathrm{c}]}$ & $\mathbf{1 4}$ & 7 & $85(3)$ \\
\hline
\end{tabular}

[a] Reactions were performed using $35 \mathrm{mM}$ of substrate, $20 \%$ mol TEMPO at $30{ }^{\circ} \mathrm{C}$ and shaken at $250 \mathrm{rpm}$ in an open Erlenmeyer with a perforated aluminum foil. [b] Conversions determined by NMR. In parenthesis, percentage detected of carboxylic acid. [c] Vigorous stirring was used instead of shaking since conversions dropped considerably under general conditions. 


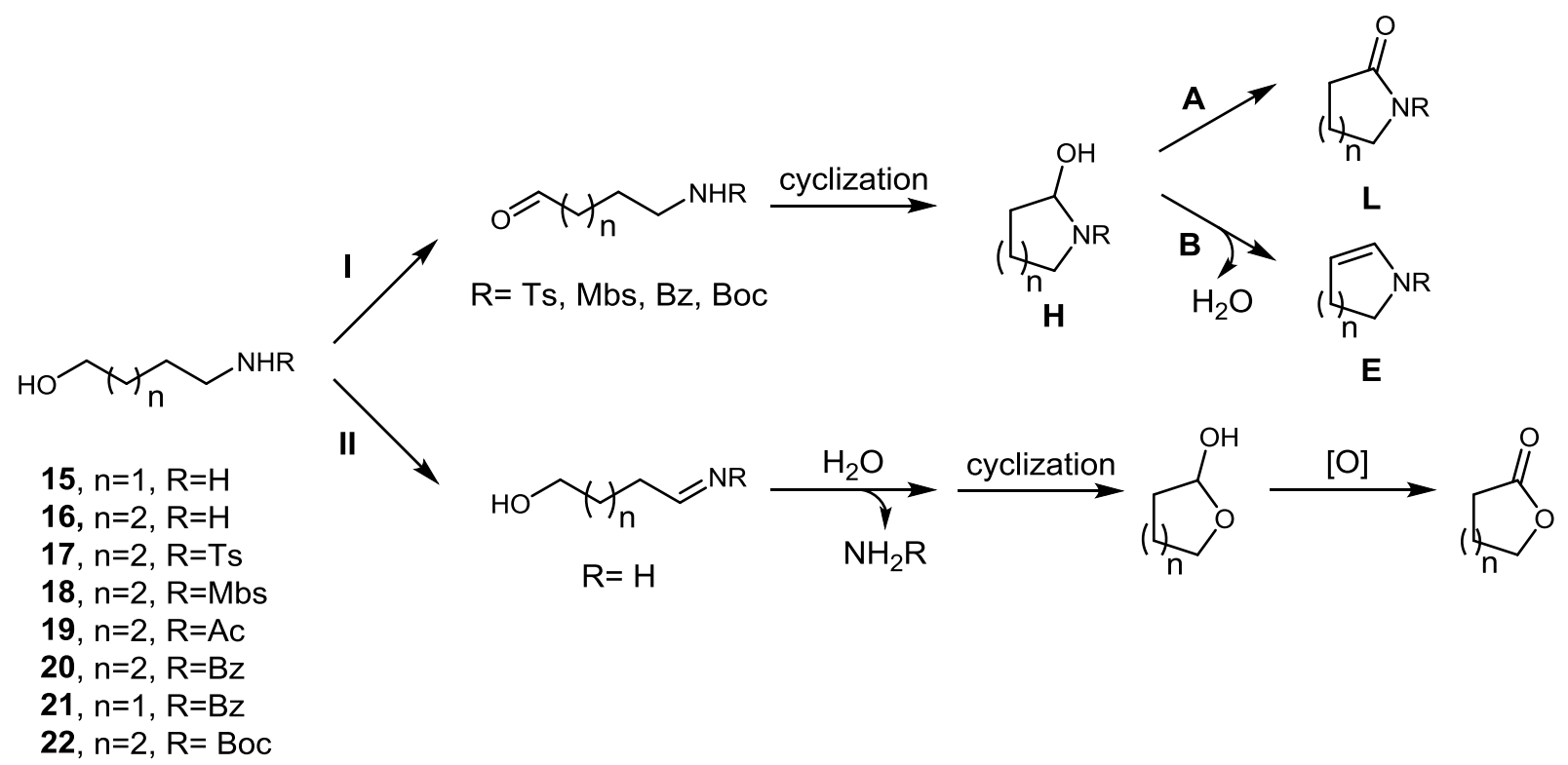

Scheme 3. Representation of the two possible routes (I, II) for the oxidation of amino alcohols 15-22. Pathway I corresponds to the oxidation of the hydroxyl group that leads to the hemiaminal $(\mathbf{H})$. Then, route $\mathbf{A}$ leads to the formation of the lactam (L) and route B leads to the enamine (E). Pathway II corresponds to the oxidation of the amino group which finally affords the lactone through hemiacetal oxidation.

Oxidation of amino alcohols. Encouraged by recent Bäckvall's results ${ }^{[24]}$ and other oxidation examples on benzylic amines, ${ }^{[25]}$ we became interested in extending our methodology to several amino alcohols (15-22, Scheme 3) to obtain the corresponding lactams. In this way, we reasoned that the oxidation of the hydroxyl group would be favored and, similarly to the diol strategy, a spontaneous cyclization process followed by reoxidation would lead to the desired lactams (Route IA, Scheme 3). However, when commercially available 4aminobutan-1-ol (15) and 5-aminopentan-1-ol (16) were used as substrates, the formation of the lactone surrogates (butyro- and valerolactone, respectively) were detected as the sole products $(>97 \%$, Route II, Scheme 3). This result can be explained if the oxidation would take place in the $\mathrm{C}-\mathrm{N}$ bond forming an imine which consequently is hydrolyzed giving access to the hydroxy aldehyde. Then, an intramolecular cyclization and reoxidation of the hemiacetal can take place. At this point, it is interesting to highlight that primary amines can be chemoselectively oxidized by this system in the presence of hydroxyl groups, transformation which is rarely observed by other chemical means. ${ }^{[26]}$

Based on these results, we decided to turn our attention to $N$-substituted amino alcohols 17-22 in order to push the reaction towards the oxidation of the hydroxy group since the formation of an imine could not be favored in such cases. ${ }^{[24]}$ We employed biphasic media since most of the protected amino alcohols showed reduced solubility in buffered solutions and therefore lower conversions were achieved. ${ }^{[27]}$ In this way, when $N$-tosylated derivative
17 was used as substrate in a MTBE/buffer solution (1:1), the oxidation reaction was directed towards the $\mathrm{C}-\mathrm{O}$ bond. Thus, the unstable aldehyde cyclized in situ affording the hemiaminal (H, Route I) with $91 \%$ conversion (Table 3, entry 1). However, no overoxidation to form the lactam was feasible under the tested conditions. In fact, when the oxidation of 17 was tried under more drastic conditions $\left(40{ }^{\circ} \mathrm{C}\right)$, and longer reaction times (Table 3 , entry 2 ), the formation of the corresponding enamine was exclusively detected (E, Route IB). It is worth mentioning that hemiaminals are important building blocks for the preparation of $\omega$-unsaturated alcohols or amines and their synthesis are not trivial. ${ }^{[28]}$ Remarkably, the use of other oxidative conventional methods such NaOCl/TEMPO, PCC or Dess-Martin reagent led to a mixture of products or no conversions (see Figure S5 in Supporting Information). These results were reproduced when $\mathbf{1 8}$, the $N$-protected derivative with the 4-methoxybenzenesulfonyl group (Mbs), was used as substrate (Table 3, entries 3 and 4). Therefore, the influence of other protecting groups was investigated on the oxidation reaction. Thus, we could observe that groups such as acetyl or benzoyl seemed to be more appropriate to access the desired path IA probably due to electronic issues. Unfortunately, acetylated compound $\mathbf{1 9}$ gave access to volatile intermediates and it was difficult to obtain reproducible results. The hydroxy amide $\mathbf{2 0}$ was found so far to be the most convenient substrate to obtain the corresponding 6-membered ring lactam (Table 3, entry 5). Besides, a mixture of hemiaminal and lactam was still detected. 
Table 3. Aerobic oxidation of protected amino alcohols. ${ }^{[\mathrm{a}]}$

\begin{tabular}{llllll}
\hline Entry & $\mathrm{R}$ & $\mathrm{n}$ & $\mathrm{t}[\mathrm{h}]$ & conv & $\begin{array}{l}\text { Ratio } \\
{[\mathrm{H}: \mathrm{E}: \mathrm{L}]}\end{array}$ \\
\hline 1 & Ts (17) & 2 & 18 & 91 & $1: 0: 0$ \\
$2^{[\mathrm{b}]}$ & Ts (17) & 2 & 28 & 95 & $0: 1: 0$ \\
\hline 3 & Mbs (18) & 2 & 18 & 90 & $1: 0: 0$ \\
$4^{[\mathrm{b}]}$ & Mbs (18) & 2 & 28 & 95 & $1: 15.7: 0$ \\
\hline 5 & Bz (20) & 2 & 18 & 92 & $1: 0: 2$ \\
6 & Bz (21) & 1 & 18 & 63 & $-[\mathrm{cc}]$ \\
7 & Boc (22) & 2 & 18 & 25 & $1: 0: 0$ \\
$8^{[\mathrm{d}]}$ & Ts $(\mathbf{1 7})$ & 2 & 18 & $>97$ & $0: 0: 1$ \\
$9^{[\mathrm{e}]}$ & Ts $(\mathbf{1 7})$ & 2 & 18 & $>97$ & $0: 1: 2.7$ \\
$10^{[\mathrm{f}]}$ & Ts $(\mathbf{1 7})$ & 2 & 18 & $>97$ & $1: 0: 0$ \\
\hline
\end{tabular}

[a] Reactions were conducted using 35-50 mM substrate, $30 \%$ mol TEMPO and MTBE (25 or $50 \% \mathrm{v} / \mathrm{v})$ at $30^{\circ} \mathrm{C}$. [b] Reaction performed at $40{ }^{\circ} \mathrm{C}$. [c] A mixture of different products was detected. [d] Reaction was performed at 110 ${ }^{\circ} \mathrm{C}$ using Shvo's catalyst as previously reported. ${ }^{[24]}$ [e] Reaction performed at $110^{\circ} \mathrm{C}$ in biphasic media using the Shvo's catalyst. [f] Reaction carried out at $40^{\circ} \mathrm{C}$ using the Shvo's catalyst in organic medium.

At this point, we thought that the five-membered counterpart could facilitate the cyclization step, therefore maximizing the formation of the lactam. However, when we prepared the corresponding $N$ benzoyl-4-aminopentan-1-ol (21) and we treated it under the same conditions described above, a distribution of different products was obtained (Table 3 , entry 6). Another protecting group (22, $\mathrm{R}=\mathrm{Boc}$ ) was examined observing lower conversions and the corresponding hemiaminal as the only final product (Table 3, entry 7).

In order to evaluate whether the formation of the lactam was impeded under aqueous conditions, we decided to study our catalytic system in detail and compare it with Bäckvall's system under both organic and aqueous conditions (Table 3, entries 8-10). Although the catalytic systems differ, we observed that the dehydrogenative amide formation was disfavored in aqueous or biphasic media, especially at low reaction temperatures where the hydrogen loss from the Shvo's catalyst does not occur in acceptordriven systems, observing in the latter case a significant percentage of enamine (Table 3 , entry 9). Additionally, when Bäckvall's reaction was performed at lower temperatures, the hemiaminal was observed as the only product showing that the lactam formation was disfavored under mild conditions (Table 3, compare entries 8 and 10).

Furthermore, the scalability of these reactions is another indispensable issue for the development of an economic process. With this idea in mind, we decided to scale up the oxidation of 17 on a $0.3 \mathrm{~g}$ scale obtaining the corresponding hemiaminal in conversion $>80 \%$ after $20 \mathrm{~h}$.

\section{Conclusions}

In conclusion, we have demonstrated that laccase from Trametes versicolor/TEMPO is an efficient and robust catalytic system with broad substrate scope for regio- and chemoselective oxidative processes of primary alcohols, diols and amino alcohols. This system is able to work in buffer solution in the absence of exogenous bases or additional ligands, but also accepts biphasic media, which is desirable in cases where substrates are hydrophobic. Interestingly, the use of an organic cosolvent allows lowering the amount of TEMPO, improving the atom efficiency of the system. Gratifyingly, oxidations are conducted in aqueous solutions under mild conditions using ambient air, in contrast to other tested chemical methods, leading to valuable compounds in very good to excellent conversions. Additionally, this methodology has shown to be chemoselective in the oxidation of unprotected primary amines in the presence of hydroxyl groups, a transformation which is rarely achieved by other chemical methods. On the contrary, by forming the corresponding protected amino alcohols, the reaction is driven towards the oxidation of the hydroxyl group leading to interesting hemiaminals in the case of $N$-sulfonyl derivatives. The preparation of the lactam was found challenging although by tuning the protecting group, we could detect its formation.

\section{Experimental Section}

\section{General procedure for the oxidation of diols 5-10}

To a solution of substrate $5-10(0.22 \mathrm{mmol})$ in $50 \mathrm{mM}$ citrate buffer $\mathrm{pH} 5.5$ and MTBE $(50 \% \mathrm{v} / \mathrm{v}, 7 \mathrm{~mL})$, was added TEMPO $(3.4 \mathrm{mg}, 0.022 \mathrm{mmol})$. The reaction mixture was stirred for a few minutes to dissolve all reagents. Then, the laccase was added $(13 \mathrm{U} / \mathrm{mL})$. The reaction mixture was stirred at $30{ }^{\circ} \mathrm{C}$ for $12 \mathrm{~h}$. After that time, the reaction was extracted with $\mathrm{CH}_{2} \mathrm{Cl}_{2}(2 \times 5 \mathrm{~mL})$. The combined organic layers were washed with brine and dried over $\mathrm{Na}_{2} \mathrm{SO}_{4}$. Crudes were analyzed by NMR.

\section{General procedure for the oxidation of alcohols 11-14}

To a solution of substrate 11-14 $(0.22 \mathrm{mmol})$ in $50 \mathrm{mM}$ citrate buffer pH 5.5 (7 mL), was added TEMPO (0.044 $\mathrm{mmol})$. The reaction mixture was stirred for a few minutes to dissolve all material. Then, the laccase was added (13 $\mathrm{U} / \mathrm{mL}$ ). The flask was covered by perforated aluminium foil and the reaction was stirred at $30{ }^{\circ} \mathrm{C}$ in a shaker $(250$ $\mathrm{rpm})$ for the time indicated in Table 2 of the manuscript $(2.5-7 \mathrm{~h})$. For substrate $\mathbf{1 4}$, the reaction was stirred vigorously to obtain good conversions. The reaction was extracted with $\mathrm{CH}_{2} \mathrm{Cl}_{2}(2 \times 5 \mathrm{~mL})$. The combined organic layers were washed with brine and dried over $\mathrm{Na}_{2} \mathrm{SO}_{4}$. Crudes were analyzed by NMR.

General protocol for the aerobic oxidation of $\mathrm{N}$ protected amino alcohols 17-22 using laccase from Tramentes versicolor/TEMPO as the catalytic system 
To a solution of the $N$-protected amino alcohols 17-22 $(0.085 \mathrm{mmol})$ in $1.7-2.5 \mathrm{~mL}$ of citrate buffer/MTBE [3:1 or $1: 1(\mathrm{v} / \mathrm{v})]$, TEMPO (4.0 mg, $0.026 \mathrm{mmol})$ was added. The reaction mixture was stirred until total dissolution of the reagents. Then, laccase from Trametes versicolor (26 $\mathrm{U} / \mathrm{mL}$ ) was added and the reaction stirred vigorously. The reaction was stirred at $30^{\circ} \mathrm{C}$ or $40^{\circ} \mathrm{C}$ as indicated in Table 3. The reaction crude was extracted with $\mathrm{CH}_{2} \mathrm{Cl}_{2}(2 \times 5$ $\mathrm{mL}$ ) and the organic layer was dried over $\mathrm{Na}_{2} \mathrm{SO}_{4}$ and concentrated under vacuum, measuring the conversions by NMR.

\section{Acknowledgements}

This research is part of BIONEXGEN project (grant agreement 266025) sponsored by the European Union inside the $7^{\text {th }}$ Framework Programme (FP7 2007-2013). Financial support from MICINN (Project MICINN-12-CTQ2011-24237) is also gratefully acknowledged. We thank CLEA Technologies and Lentikats for providing some of the screened oxidases. L.M.-M. thanks the Principado de Asturias for her predoctoral fellowship Severo Ochoa. I.L. thanks the Spanish MICINN for personal funding (Ramón y Cajal Program).

\section{References}

[1] Modern Oxidation Methods, 2nd ed., (Ed.: J.-E. Bäckvall), Wiley-VCH, Weinheim, 2011.

[2] For some recent reviews see: a) M. J. Schultz, M. S. Sigman, Tetrahedron 2006, 62, 8227-8241; b) C. P. Vinod, K. Wilson, A. F. Lee, J. Chem. Technol. Biotechnol. 2011, 86, 161-171; c) F. Cardona, C. Parmeggiani, Green Chem. 2012, 14, 547-564.

[3] a) W. Kroutil, H. Mang, K. Edegger, K. Faber, $A d v$. Synth. Catal. 2004, 346, 125-142; b) Modern Biooxidation. Enzymes, Reactions and Applications, (Eds.: R. D. Schmid, V. B. Urlacher), Wiley-VCH, Weinheim, 2007; c) F. Hollmann, I. W. C. E. Arends, K. Buehler, A. Schallmey, B. Bühler, Green Chem. 2011, 13, 226-265; d) N. J. Turner, Chem. Rev. 2011, 111, 4073-4087; e) D. Romano, R. Villa, F. Molinari, ChemCatChem 2012, 4, 739-749.

[4] a) E. I. Solomon, U. M. Sundaram, T. E. Machonkin, Chem. Rev. 1996, 96, 2563-2605; b) H. Claus, Arch. Microbiol. 2003, 179, 145-150; c) S. G. Burton, Curr. Org. Chem. 2003, 7, 1317-1331; d) H. Claus, Micron 2004, 35, 93-96; e) L. Quintanar, C. Stog, A. B. Taylor, P. J. Hart, D. J. Kosman, E. I. Solomon, Acc. Chem. Res. 2007, 40, 445-452; f) P. Giardina, V. Faraco, C. Pezzella. A. Piscitelli, S. Vanhulle, G. Sannia, Cell. Mol. Life Sci. 2010, 67, 369-385.

[5] a) R. Bourbonnais, M. G. Paice, FEBS Lett. 1990, 267, 99-102; b) E. Srebotnik, K. E. Hammel, J. Biotechnol. 2000, 81, 179-188; c) J. Sealey, A. J. Ragauskas, J. Wood Chem. Technol. 1998, 18, 403-416; d) M. Fabbrini, C. Galli, P. Gentili, J. Mol. Catal. B: Enzym. 2002, 16, 231-240; e) C. Galli, P. Gentili, J. Phys. Org. Chem. 2004, 17, 973-977; f) P. Astolfi, P. Brandi, C. Galli, P. Gentili, M. F. Gerini, L. Greci, O. Lanzalunga, New J. Chem. 2005, 29, 1308-1317; g) S. Camarero, D. Ibarra, M. J. Martínez, Appl. Environ. Microbiol. 2005,
71, 1775-1784; h) I. W. C. E. Arends, Y.-X. Li, R. Ausan, R. A. Sheldon, Tetrahedron 2006, 62, 66596665; i) S. Camarero, A. I. Cañas, P. Nousiainen, E. Record, A. Lomascolo, M. J. Martínez, A. T. Martínez, Environ. Sci. Technol. 2008, 42, 6703-6709.

[6] For mechanistic studies of the laccase/TEMPO system, see: a) F. d'Acunzo, P. Baiocco, M. Fabbrini, C. Galli, P. Gentili, Eur. J. Org. Chem. 2002, 4195-4201; b) S. A. Tromp, I. Matijošytė, R A. Sheldon, I. W. C. E. Arends, G. Mul, M. T. Kreutzer, J. A. Moulijn, S. de Vries, ChemCatChem 2010, 2, 827-833.

[7] a) M. Fabbrini, C. Galli, P. Gentili, D. Macchitella, Tetrahedron Lett. 2001, 42, 7551-7553; b) M. Marzorati, B. Danieli, D. Haltrich, S. Riva, Green Chem. 2005, 7, 310-315.

[8] a) A. Barilli, F. Belinghieri, D. Passarella, G. Lesma, S. Riva, A. Silvani, B. Danieli, Tetrahedron: Asymmetry 2004, 15, 2921-2925; b) K. Kędziora, A. DíazRodríguez, I. Lavandera, V. Gotor-Fernández, V. Gotor, Green Chem. 2014, 16, 2448-2453.

[9] a) E. E. Ferrandi, D. Monti, I. Patel, R. Kittl, D. Haltrich, S. Riva, R. Ludwig, Adv. Synth. Catal. 2012, 354, 2821-2828; b) P. Könst, S. Kara, S. Kochius, D. Holtmann, I. W. C. E. Arends, R. Ludwig, F. Hollmann, ChemCatChem 2013, 5, 3027-3032.

[10] F. Minisci, F. Recupero, A. Cecchetto, C. Gambarotti, C. Punta, R. Faletti, R. Paganelli, G. F. Pedulli, Eur. J. Org. Chem. 2004, 109-119.

[11] a) P. L. Anelli, C. Biffi, F. Montanari, S. Quici, J. Org. Chem. 1987, 52, 2559-2562; for a review on oxidations mediated by nitroxyl derivatives, see: b) R. A. Sheldon, I. W. C. E. Arends, Adv. Synth. Catal. 2004, 346, 1051-1071; for industrial applications of TEMPO, see: c) R. Ciriminna, M. Pagliaro, Org. Process Res. Dev. 2010, 14, 245-251.

[12] For selected recent publications, see: a) S. France, A. Weatherwax, A. E. Taggi, T. Lectka, Acc. Chem. Res. 2004, 37, 592-600; b) L.-S. Wang, H.-C. Chen, Z.-C. Xiong, X.-B. Pang, C.-D. Xiong, Macromol. Mater. Eng. 2010, 295, 381-385; c) W. R. H. Wright, R. Palkovits, ChemSusChem 2012, 5, 1657-1667; d) P. Azadi, R. Carrasquillo-Flores, Y. J. Pagán-Torres, E. I. Gürbüz, R. Farnood, J. A. Dumesic, Green Chem. 2012, 14, 1573-1576; e) D. M. Alonso, S. G. Wettstein, J. A. Dumesic, Green Chem. 2013, 15, 584-595.

[13] For reviews dealing with applications of laccases in biotechnology and organic chemistry, see: a) S. Riva, Trends Biotechnol. 2006, 24, 219-226; b) S. R. Couto, J. L. T. Herrera, Biotech. Adv. 2006, 24, 500-513; c) S. Witayakran, A. J. Ragauskas, Adv. Synth. Catal. 2009, 351, 1187-1209; d) T. Kudanga, G. S. Nyanhongo, G. M. Guebitz, S. Burton, Enzyme Microb. Technol. 2011, 48, 195-208; e) Z. Yang, Synlett 2012, 23, 2574-2575; f) M. Mogharabi, M. A. Faramarzi, Adv. Synth. Catal. 2014, 356, 897-927.

[14] A. Díaz-Rodríguez, I. Lavandera, S. Kanbak-Aksu, R. A. Sheldon, V. Gotor, V. Gotor-Fernández, Adv. Synth. Catal. 2012, 354, 3405-3408. 
[15] A. C. Herath, J. Y. Becker, Electrochim. Acta 2008, 53, 4324-4330.

[16] J. M. Hoover, S. S. Stahl, J. Am. Soc. Chem. 2011, 133, 16901-16910.

[17] a) J. Rodakiewicz-Nowak, S. M. Kasture, B. Dudek, J. Haber, J. Mol. Catal. B: Enzym. 2000, 11, 1-11; b) F. d'Acunzo, A. M. Barreca, C. Galli, J. Mol. Catal. B: Enzym. 2004, 31, 25-30; c) L. Baratto, A. Candido, M. Marzorati, F. Sagui, S. Riva, B. Danieli, J. Mol. Catal. B: Enzym. 2006, 39, 3-8; d) S. Ncanana, L. Baratto, L. Roncaglia, S. Riva, S. G. Burton, Adv. Synth. Catal. 2007, 349, 1507-1513.

[18] J. Rodakiewicz-Nowak, Top. Catal. 2000, 11-12, 419-434.

[19] For more examples where different cosolvents have been used in laccase-mediated reactions, see: a) A. M. Barreca, M. Fabbrini, C. Galli, P. Gentili, S. Ljunggren, J. Mol. Catal. B: Enzym. 2003, 26, 105-110; b) A. Intra, S. Nicotra, S. Riva, B. Danieli, Adv. Synth. Catal. 2005, 347, 973-977; c) M. Zumárraga, T. Bulter, S. Shleev, J. Polaina, A. Martínez-Arias, F. J. Plou, A. Ballesteros, M. Alcalde, Chem. Biol. 2007, 14, 1052-1064; d) N. A. Mohidem, H. B. Mat, Bioresour. Technol. 2012, 114, 472-477.

[20] For Cu/TEMPO examples: a) M. F. Semmelhack, C. R. Schmid, D. A. Cortés, C. S. Chou, J. Am. Chem. Soc. 1984, 106, 3374-3376; b) G. Ragagnin, B. Betzemeier, S. Quici, P. Knochel, Tetrahedron 2002, 58, 3985-3991; c) P. Gamez, I. W. C. E. Arends, R. A. Sheldon, J. Reedijk, Adv. Synth. Catal. 2004, 346, 805811; d) D. Geisslmeir, W. G. Jary, H. Falk, Monatsh. Chem. 2005, 136, 1591-1599; e) N. Jiang, A. J. Ragauskas, J. Org. Chem. 2006, 71, 7087-7090; f) S. Mannam, S. K. Alamsetti, G. Sekar, Adv. Synth. Catal. 2007, 349, 2253-2258; g) P. J. Figiel, A. Sibaouih, J. U. Ahmad, M. Nieger, M. T. Räisanen, M. Leskelä, T. Repo, Adv. Synth. Catal. 2009, 351, 2625-2632.

[21] P. Gamez, I. W. C. E. Arends, J. Reedijk, R. A. Sheldon, Chem. Commun. 2003, 2414-2415.
[22] For methods with $\mathrm{Pd}(\mathrm{OAc})_{2}$ : a) T. Nishimura, T. Onoue, K. Ohe, S. Uemura, J. Org. Chem. 1999, 64, 6750-6755; b) G.-J. Brink, I. W. C. E. Arends, M. Hoogenraad, G. Verspui, R. A. Sheldon, Adv. Synth. Catal. 2003, 345, 1341-1352; for methods with $\mathrm{Ru}-$ based catalysts, c) A. Dijksman, A. Marino-González, A. M. Payeras, I. W. C. E. Arends, R. A. Sheldon, J. Am. Chem. Soc. 2001, 123, 6826-6833; d) Y. Endo, J.E. Bäckvall, Chem. Eur. J. 2011, 17, 12596-12601; for $\mathrm{Fe}\left(\mathrm{NO}_{3}\right)_{3}$ : e) S. Ma, J. Liu, S. Li, B. Chen, J. Cheng, J. Kuang, Y. Liu, B. Wan, Y. Wang, J. Ye, Q. Yu, W. Yuan, S. Yu, Adv. Synth. Catal. 2011, 353, 1005-1017.

[23] For instance, see: a) T. Morihara, T. Chu, O. Ubeda, W. Beech, G. M. Cole, J. Neurochem. 2002, 83, 10091012; b) J. L. Eriksen, S. A. Sagi, T. E. Smith, S. Weggen, P. Das, D. C. McLendon, V. V. Ozols, K. W. Jessing, K. H. Zavitz, E. H. Koo, T. E. Golde, J. Clin. Invest. 2003, 112, 440-449.

[24] B. P. Babu, Y. Endo, J.-E. Bäckvall, Chem. Eur. J. 2012, 18, 11524-11527.

[25] A. Wells, M. Teria, T. Eve, Biochem. Soc. Trans. 2006, 34, 304-308.

[26] J. Srogl, S. Voltrova, Org. Lett. 2009, 11, 843-845.

[27] In these reactions we used $30 \% \mathrm{~mol}$ of TEMPO in order to push the reaction towards the formation of the lactam derivatives. In fact, when compound $\mathbf{1 7}$ was treated with $15 \%$ mol of TEMPO and the laccase, a conversion of $55 \%$ towards the hemiacetal was observed.

[28] a) K. Kawada, T. Tsushima, Heterocycles 1989, 28, 573-578; b) K. Seno, S. Hagishita, Chem. Pharm. Bull. 1989, 37, 948-954; c) S. Kamata, N. Haga, T. Tsuri, K. Uchida, H. Kakushi, H. Arita, K. Hanasaki, J. Med. Chem. 1990, 33, 229-239; d) M. Ohtani, M. Narisada, J. Med. Chem. 1990, 33, 1027-1031; e) A. B. Holmes, A. L. Smith, S. F. Williams, J. Org. Chem. 1991, 56, 1393-1405; f) C. G. Kokotos, V. K. Aggarwal, Chem. Commun. 2006, 2156-2158. 


\section{UPDATE}

Laccase/TEMPO: an efficient catalytic system for selective oxidations of primary hydroxy and amino groups in aqueous and biphasic media

Adv. Synth. Catal. Year, Volume, Page - Page

Alba Díaz-Rodríguez, Lía Martínez-Montero, Iván Lavandera, Vicente Gotor and Vicente Gotor-

Fernández*

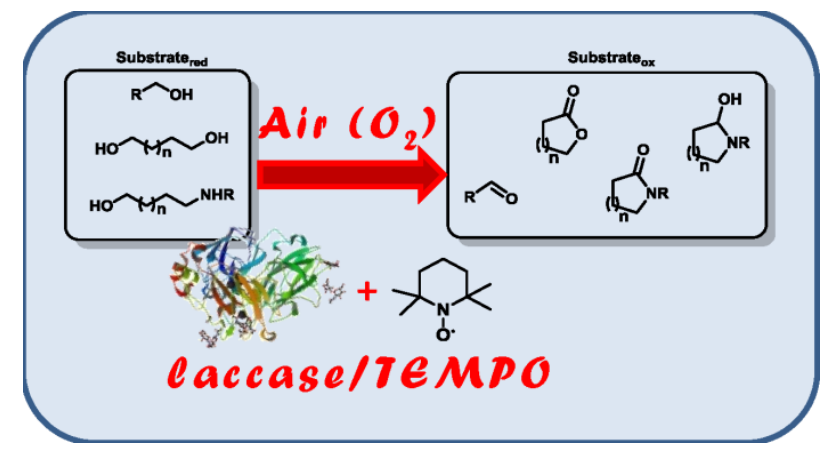

